\title{
Competitiveness of seafood enterprises: the case study of Ba-Ria-Vung-Tau province, Vietnam
}

\author{
Ai Huu $\operatorname{Tran}^{1 *}$ \\ ${ }^{1}$ Van Hien University, Dien Bien Phurong 1, Quan 3, Hồ Chí Minh 700000, Vietnam
}

\begin{abstract}
This study aims to identify and measure the impact on the Competitive capability of frozen seafood processing enterprises in BR-VT province. Research access tocompetitiveness is based on competency theory, different from previous domestic studies primarily approaching competitiveness based on traditional competition theory and value chain theory. The research model consists of 9 factors. The study was conducted with 356 survey samples of 76 frozen seafood processing enterprises, surveyed through a questionnaire.Data analysis through SPSS 24.0. The test results have 8 accepted hypothesis, the highest impact factor is the ability to access and innovate technology with $\beta=0.3328(\mathrm{p}=0.000)$ and the lowest is local infrastructure factorwith $\beta=0.067(\mathrm{p}=0.042)$, and Policy and Legal Factor with $\beta=-0.038(\mathrm{p}=0.249)$, there is not statistical significance should not be accepted.
\end{abstract}

\section{Introduction}

From a practical perspective, in Vietnam as well as other countries in the world, the fishery industry, which is an economic industry has a very important position in the cause of industrialization and modernization of the country and quickly grasp integration trends. Seafood is increasingly valued and is considered a food with many nutritional benefits [1]. Global seafood production has increased over the past decades and it is estimated that about half of the world's total seafood production is traded internationally [2].Vemand and consumption of fresh seafood have increased and it is considered to be the most important fishery product accounting for about half of the human seafood consumption market [3].

Freshness is described as the most valuable seafood attribute in all consumer markets [4] and thus creates the ability to charge high prices and gain higher profits when harvesting fresh seafood compared to processing, (e.g. Frozen or dried). In addition to the commercial value potential of harvesting nutrients and allocating from the BR-VT Sea in particular and the Vietnam Sea in general, there is also the prospect of creating employment opportunities in a newly developed country. A fishery is one of the oldest and most important manufacturing industries in the world economy. World shrimp production continues to increase for many years. FAO [8] mentioned that global shrimp production increased from

\footnotetext{
* Corresponding author: aith@vhu.edu.vn
} 
1.7 million tons in the early 1980 s to 8.2 million tons in 2018 , of which about $60 \%$ of that amount entered the national market is International [2].

In a globalized economy, competition means the ability to have a consistent and stable position in the market [5]. However, the simple observation that the life expectancy of most seafood companies is quite short because the start-up companies are often bankrupt, showing that seafood companies often do not develop competitive advantages, and also There are advantages that tend to erode over time. Much attention has also been kept to incorporating the concept of competitive advantage into capacity theory.

However, very few studies have actually addressed this to companies and the managers of the Company often deal in building and overcoming competitive advantage, in order to gain a new market share to be profitable. Political, economic, social, technological, ecological and legal factors in an ever-changing environment require organizations to link their internal capabilities with external environmental needs to achieve company goals. The mismatch between internal and external business environments is a surefire recipe for failure [6]. According to the definition of [7], a company has a competitive advantage if it has an advantage over competitors in protecting customers and protecting themselves against competitive forces.

\section{Literature review}

In a market economy, competition is a common and significant phenomenon for economic development in countries. The competition phenomenon in the seafood field has existed for a long time and the theory of competition also came out very early with the famous theoretical such as the classical competition theory, and the theory modern on competitive. These theories have clarified the nature of competition, the role and impact of competition, methods of competition, etc. In addition to classical economists and classics, competing theories attached to the famous names of the perfect theory of competition such as A. Coumot, L. Walras, Marshall...andThe Modern theory of computer like E. Hamberlin, J. Robinson, J. Schumpeter, R. Boyer, M. Agietta, M. Porter, M. Eairbank..

General literature on competitiveness research, some authors such as Flanagan et al (2007) have shown that, starting from the 1990s to Nowadays, the theory of competitiveness in the world has entered the period of "booming" with a large number of published works. The research directions on the Competitive capability through the author's study are divided into 5 main directions:

(1) Competitive capability approaching from the traditional competition theory;

(2) Competitive capability approaching from the value chain theory;

(3) Competitive capability approached according to market orientation theory;

(4) Competitive capability approached according to enterprise resource theory;

(5) Competitive capability approached according to capacity theory.From a theoretical perspective, the competitiveness of enterprises has been always a top concern not only for businesses but also a great concern of researchers both at home and abroad. According to Porter [8], the topic of competitiveness studies is usually a business or national economy, and rarely an industry. Correct definition of the term competition is a very complex process [9].

Competition theory based on IO economics [8], monopoly competitionis often based on the premise that enterprises in the same industry have uniform resources and the business strategies use. Anoop Madhok et al., [10], "Looking to the future based on action on the competitiveness of the company".

This study analyzed the theoretical background of competitiveness to develop the given perspective: 1) The theoretical formulation process was used to analyze existing definitions of competitive structure; 2) The theoretical concepts are derived from existing definitions 
and competing theories; 3) Based on the analysis, a comprehensive definition of competitiveness was proposed. The importance of clusters (cooperation between companies in "related industries") to competitive resources was analyzed by Porter $[8,9]$.

A series of articles published in major marketing and management strategy magazines has created useful insights regarding (a) the difference between a customer and market orientation, (b) for although the market orientation and customer representation are limited regularly, and (c) how the market orientation contributes to performance [9, 11]. The market approach, focusing on learning experiences in the most effective and effective way to create superior value for customers [12]. Market-oriented companies can perceive the market by creating, disseminating and responding to market information [13, 14].

According to Ketels, C.H.M. [9], industry-level competitiveness is the ability to maintain profits in domestic and international markets. From a resource-based point of view, competency is the key to maintaining a sustainable and highly competitive advantage $[5,15]$. However, enterprises are characterized by limited resources and often face competitive pressure, this pressure threatens its existence [16, 17]. Most businesses face challenges such as: technology, product innovation, customer needs and the desire to exist flexibly [18].

When enhancing a company's competitiveness by improving the value chain structure. The value chain framework has been adopted as a powerful analytical tool for strategic planning in individual business units and extends to the entire supply chain [19]. However, little attention has been paid to developing value chain thinking. Sytnyk et al. [5], examined the emergence of value chain thinking and proposed new value chain thinking in relation to a series of interconnected activities to maintain value. A value chain conceptual model is presented consisting of four steps: value discovery, value design, value distribution and value capture.

Businesses focus on the ability to use, combining assets, resources and capacity to achieve the organization's overall growth and efficiency. Barney [20] have developed management-based management competencies, focusing on the ability to use and combine assets, resources and capacity to achieve overall growth and efficiency of the organization. From a competency perspective, the integration capability provides the necessary coordination of enterprise resources and various capabilities. A company's ability is then created by combining and recombining, the integrated dynamic ability to create value in the target market through the production and use of strategic resources of companies [21].

Based on the theory of competence and independent variables inherited from Sauka and Teece $[22,23]$. The author through analysis, discussion and suggestions of the experts arranging, reviewing, making comments and these statements are the primary basis for making a research model and adding two new factors: Relationship marketing capacity and adaptive capacity in the group of factors affecting the specific competitive competence of frozen seafood processing enterprises in BR-VT province; at the same time, testing and developing the scale of these factors. This is new content that no research has been done before at BR-VT. 
Table 1. Summary of factors affecting competitiveness of seafood processing enterprises in BR-VT province.

\begin{tabular}{|c|l|c|}
\hline No. & \multicolumn{1}{|c|}{ Components of scale } & Properties of a scale \\
\hline 1 & Management and operating competency of enterprises & {$[8,24]$} \\
\hline 2 & Relationship marketing competency & Expert discussion \\
\hline 3 & Human resource competency & {$[22,23]$} \\
\hline 4 & Financial competency & {$[25,23]$} \\
\hline 5 & Competency to access and innovate technology & {$[23,26]$} \\
\hline 6 & Adaptive competency & {$[8,27]$} \\
\hline 7 & Impact on the market & {$[18,27]$} \\
\hline 8 & Laws and policies & {$[18,27]$} \\
\hline 9 & Local infrastructure & {$[18,24]$} \\
\hline 10 & Competitiveness of BR-VT province & Expert discussion \\
\hline
\end{tabular}

\section{Research hypothesis}

\subsection{Management and operating competency of the business}

According to Chi Kun Ho [25], the typical management capacity of a manager of a company or a group of workers is the contribution to the successful completion of the task. Therefore, management competence is understood here as observable characteristics such as knowledge, skills, or behavioral patterns that contribute to the successful completion of tasks. The hypothesis is that:

H1:Management and operating capacity have a positive relationship with the Competitive capability of BR - VT enterprises.

\subsection{Human resource competency}

Teece, D. [23], show that human resource capacity has a positive impact on the growth of small businesses, which increases employee skills and motivation, and ultimately leads to improved productivity and the long-term sustainability of small businesses. The hypothesis is that:

H2: Human resources capacity has a positive relationship with the Competitive capability of BR-VT enterprises.

\subsection{Financial competency}

Walters, D et al., [28] find that while growing, small businesses have less access to external finance, which makes small businesses more limited in operations and growth compared to large businesses. The hypothesis is that:

H3: Financial capacity has a positive relationship with the Competitive capability of BR-VT enterprises. 


\subsection{Relationship marketing competency}

The Relationship marketing competency, marketing affecting the Competitive capability of enterprises studies by the authors [29]. Marketing is a function that satisfies the needs of customers to achieve the goals of the business, [29].The hypothesis is that:

H4: Relationship marketing capability has a positive relationship with the Competitive capability of BR - VT enterprises.

\subsection{Competency to access and innovate technology}

Lewrick, Michael [30] think that conducting innovation activities will help businesses consolidate their competitive position compared to competitors; The innovation process changes a business to basically strengthen its internal capacity, be more flexible and adapt to market pressure than non-innovating businesses. The hypothesis is that:

H5: The competency to access and innovate technology has a positive relationship with the Competitive capability of BR - VT enterprises.

\subsection{Adaptive competency}

Adaptive competency on basis concepts of Sauka [22] are emphasizing the ability of enterprises to take appropriate actions to respond to market changes, a key feature of adaptability. The hypothesis is that:

H6: adaptive competency has a positive relationship with the Competitive capability of BR - VT enterprises.

\subsection{Impact on the market}

Momaya [31] said that the theory of dynamical evaluates enterprise competencies that can create competitive advantage in rapidly changing environments. Moreover, Momaya [31] shows that adaptive capacity allows businesses to create and maintain profits in a rapidly changing environment. The hypothesis is that:

H7: Impact on the market has a positive relationship with the Competitive capability of BR - VT enterprises.

\subsection{Laws and policies}

According to Lumpkin and Dess [32] the growth of small and medium enterprises is affected by its business environment. Porter, M.E. et al. [8] identified competition as one of the major impediments to the growth of small businesses. Momaya [31] notes that an unfavorable tax system, complex rules and regulations can hinder a lot of the growth of small companies. The hypothesis is that:

H8: Laws and policies has a positive relationship with the Competitive capability of BR - VT enterprises [30]

\subsection{Local infrastructure}

Public infrastructure is often seen as a cornerstone of building an economy conducted an analysis of the implementation of sustainable development policies [14]. They noted that infrastructure development is one of the most important aspects in the field of planning. National strategy for sustainable space socio-economic development. The hypothesis is that: 
H9:Local infrastructure has a positive relationship with the Competitive capability of $\mathrm{BR}$ - VT enterprises

\section{Methodology}

The research method used is a mixed research method, combining qualitative and quantitative research methods. The data processing tool used in the study is SPSS software with the main tools such as: Cronbach's Alpha coefficient; Exploratory Factor Analysis (EFA), CFA; variance analysis; Linear regression analysis, control variables analysis. Includes:

\subsection{Qualitative research}

Using interviews with managers who have a real sense of the competitiveness of frozen seafood processing enterprise with open-ended questions to collect initial data to determine competitiveness characteristics of frozen seafood processing enterprise, factors affecting the competitiveness of frozen seafood processing enterprise BR-VT.

Group discussions (50 people with good knowledge of research issues) and hand-to-face interviews with fisheries management experts and fishery managers to develop, adjust and conduct in-depth interviews fisheries administrators by semi-structured interview method to clarify the results of qualitative research.

\subsection{Quantitative research}

Quantitative research to build a scale and determine the level of factors affecting the Competitive capability of frozen seafood processing enterprises. Using the survey method through the distribution of questionnaires to collect initial data from managers at frozen seafood processing enterprises in BR-VT province.

\subsection{Statistics and analysis}

Quantitative research methods are used in this study. Theoretical models have nine independent variables measured by 41 observed variables and one dependent variable measured by 03 observed variables. The Likert scale recorded as 1 - strongly disagree, and 5 - strongly agree.

Data analysis: Reliability and validity are determined through the calculation of Cronbach alpha coefficients using step-by-step, maximizing the reliability of the scale at 0.70 [33]. Cronbach coefficient alpha is accepted (exceeding 0.7); the measuring instruments are quite reliable. This study uses exploratory factor analysis (EFA) and validation factor analysis (CFA) and linearregression analysisto test hypothesis. Testing the fit of the hypothesized structural model, revised model.

\section{Results}

The survey was conducted from April to August 2019, via direct paper questionnaire or email to respondents. 450 direct questionnaires were distributed, resulting in a total of 408 questionnaires. After cleaning the data, 43 questionnaires were invalid and not quality (12 tables lacking information; 14 tables selected more than 1 answer for the type of question 1 choice; 17 questionnaires answered, lacking considered by the same evaluation for most 
questions), there are 365 questionnaires used for analysis and verification, reaching $89.46 \%$.

Specifically, the sample structure selected was 365 samples selected as follows:

The number of managers surveyed (the number of sample units surveyed) of the unit is assessed based on the size of the enterprise. Small businesses account for $15 \%-20 \%$; Medium enterprises account for 50\% - $70 \%$; Largeenterprises account for $15 \%-10 \%$.

- The number of managers surveyed by gender is limited within: Female from 30\% $-35 \%$, Male from $35 \%-65$

- The number of managers surveyed by age from $25 \mathrm{~T}-35 \mathrm{~T}$ is $10 \%-15 \%$; from $35 \mathrm{~T}-45 \mathrm{~T}$ is $30 \%-50 \%$; over $45 \mathrm{~T}$ is $20 \%-30 \%$.

- Number of managers surveyed belongs to positions. Board of Directors of the Company, Director of Enterprise is 3\% - 5\%; The head of the professional department is $10 \%-15 \%$ and the management of the workshop and production committee. These are the subjects who are knowledgeable about the business activities of the seafood enterprise and are responsible for the results of production and business activities. of the labor resources enterprises

Table 2. Sample characteristics of the survey.

\begin{tabular}{|c|c|c|c|c|c|}
\hline \multicolumn{6}{|c|}{ SCALE } \\
\hline & & Frequency & Percent & Valid Percent & Cumulative Percent \\
\hline \multirow{3}{*}{ Valid } & DN > 500 Labors & 292 & 80.0 & 80.0 & 80.0 \\
\hline & DN $<500$ Labor & 73 & 20.0 & 20.0 & 100.0 \\
\hline & Total & 365 & 100.0 & 100.0 & \\
\hline \multicolumn{6}{|c|}{ SEX } \\
\hline & & Frequency & Percent & Valid Percent & Cumulative Percent \\
\hline \multirow[t]{3}{*}{ Valid } & Male & 323 & 88.5 & 88.5 & 88.5 \\
\hline & Female & 42 & 11.5 & 11.5 & 100.0 \\
\hline & Total & 365 & 100.0 & 100.0 & \\
\hline \multicolumn{6}{|c|}{$\begin{array}{l}\text { POSITION } \\
\end{array}$} \\
\hline & & Frequency & Percent & Valid Percent & Cumulative Percent \\
\hline \multirow[t]{4}{*}{ Valid } & Board of manager & 37 & 10.1 & 10.1 & 10.1 \\
\hline & Chief department & 193 & 52.9 & 52.9 & 63.0 \\
\hline & Management of factory & 135 & 37.0 & 37.0 & 100.0 \\
\hline & Total & 365 & 100.0 & 100.0 & \\
\hline
\end{tabular}

The testing results show that all scales have Cronbach Alpha reliability level $>0.7$ and none of the variables have a total correlation coefficient of $<0.4$. Thus, the results of measuring scales by Cronbach Alpha tool showed that all scales were reliable and suitable to continue being included in EFA factor analysis.

After eliminating the observed variables LP4 (the scales of law and policy), the scale meets the reliability coefficient standard. Results of the discovery factor analysis (EFA) the second time shows that 40 observed variables in 9 components of the scale of factors related to the Competitive capability of the BR-VT enterprises were extracted into 9 components. KMO coefficient $=0.743$, so EFA is consistent with Bartlett's data and Chiquare statistics reaching 12224.988 with significance level Sig $=0.000$; so the observed variables are correlated with each other in terms of the overall scope. The extracted variance is $71.983 \%$, showing that the nine factors extracted were explained $71.983 \%$ of the variation of the data, at the eigenvalue coefficient equal to 1.192 . 
Table 3. Cronbach's Alpha test of reliability coefficient before EFA analysis.

\begin{tabular}{|c|l|c|c|c|}
\hline $\mathrm{N}_{0}$ & \multicolumn{1}{|c|}{ Scales } & $\begin{array}{c}\text { Observed } \\
\text { Variables }\end{array}$ & $\begin{array}{c}\text { Crobach } \\
\text { alpha }\end{array}$ & $\begin{array}{c}\text { Corrected item- } \\
\text { total correlation }\end{array}$ \\
\hline 1 & $\begin{array}{l}\text { Management and operating competency of } \\
\text { enterprises (MOC) }\end{array}$ & 5 & 0.923 & 0.721 \\
\hline 2 & $\begin{array}{l}\text { Relationship marketing competency } \\
\text { (RMC) }\end{array}$ & 4 & 0.830 & 0.587 \\
\hline 3 & Human resource competency (HRC) & 5 & 0.912 & 0.709 \\
\hline 4 & Financial competency (FC) & 4 & 0.877 & 0.656 \\
\hline 5 & $\begin{array}{l}\text { Competency to access and innovate } \\
\text { technology (CAIT) }\end{array}$ & 4 & 0.903 & 0.707 \\
\hline 6 & Adaptive competency (AC) & 5 & 0.881 & 0.606 \\
\hline 7 & Impact on the market (IM) & 4 & 0.855 & 0.621 \\
\hline 8 & Laws and policies (LP) & 5 & 0.830 & 0.507 \\
\hline 9 & Local infrastructure (LI) & 4 & 0.799 & 0.538 \\
\hline 10 & Competitiveness of BR-VT firms (CF) & 45 & & \\
\hline & Total & 5 & \\
\hline
\end{tabular}

Table 4. Summary of scale verification results.

\begin{tabular}{|c|c|c|c|c|}
\hline Component & $\begin{array}{c}\text { Variables } \\
\text { observe }\end{array}$ & $\begin{array}{c}\text { CronbachAl } \\
\text { pha }\end{array}$ & $\begin{array}{c}\text { Extracted } \\
\text { variance }(\%)\end{array}$ & Evaluate \\
\hline $\begin{array}{l}\text { Management and operating competency } \\
\text { of enterprises }\end{array}$ & 5 & 0.923 & \multirow{9}{*}{71.988} & \multirow{10}{*}{ Qualified } \\
\hline Relationship marketing competency & 4 & 0.830 & & \\
\hline Human resource competency & 5 & 0.913 & & \\
\hline Financial competency & 4 & 0.877 & & \\
\hline $\begin{array}{l}\text { Competency to access and innovate } \\
\text { technology }\end{array}$ & 4 & 0.903 & & \\
\hline Adaptive competency & 5 & 0.830 & & \\
\hline Impact on the market & 4 & 0.855 & & \\
\hline Laws and policies & 4 & 0.805 & & \\
\hline Local infrastructure & 5 & 0.826 & & \\
\hline Competitiveness of BR-VT firms & 4 & 0.795 & 62.337 & \\
\hline
\end{tabular}

The CFA results show that all standardized estimates of factor load factors are of high value. The criteria to evaluate the suitability with the survey data are quite high, respectively: Chi-square $=748,003 \mathrm{df}=337 ; \mathrm{p}=0,000$; Chi- square $/ \mathrm{df}=1,820(<2) ; \mathrm{GFI}=$ $0.918(>0.9)$; TLI $=0.921(>0.9)$; CFI $=0.935(>0.9)$; RMSEA $=0.057(<0.08)$. As such, this is evidence that affirms multidirectional, converged values, discriminatory values and appropriateness of the scale of factors of competitive competence 
Table 5. Regression Analysis.

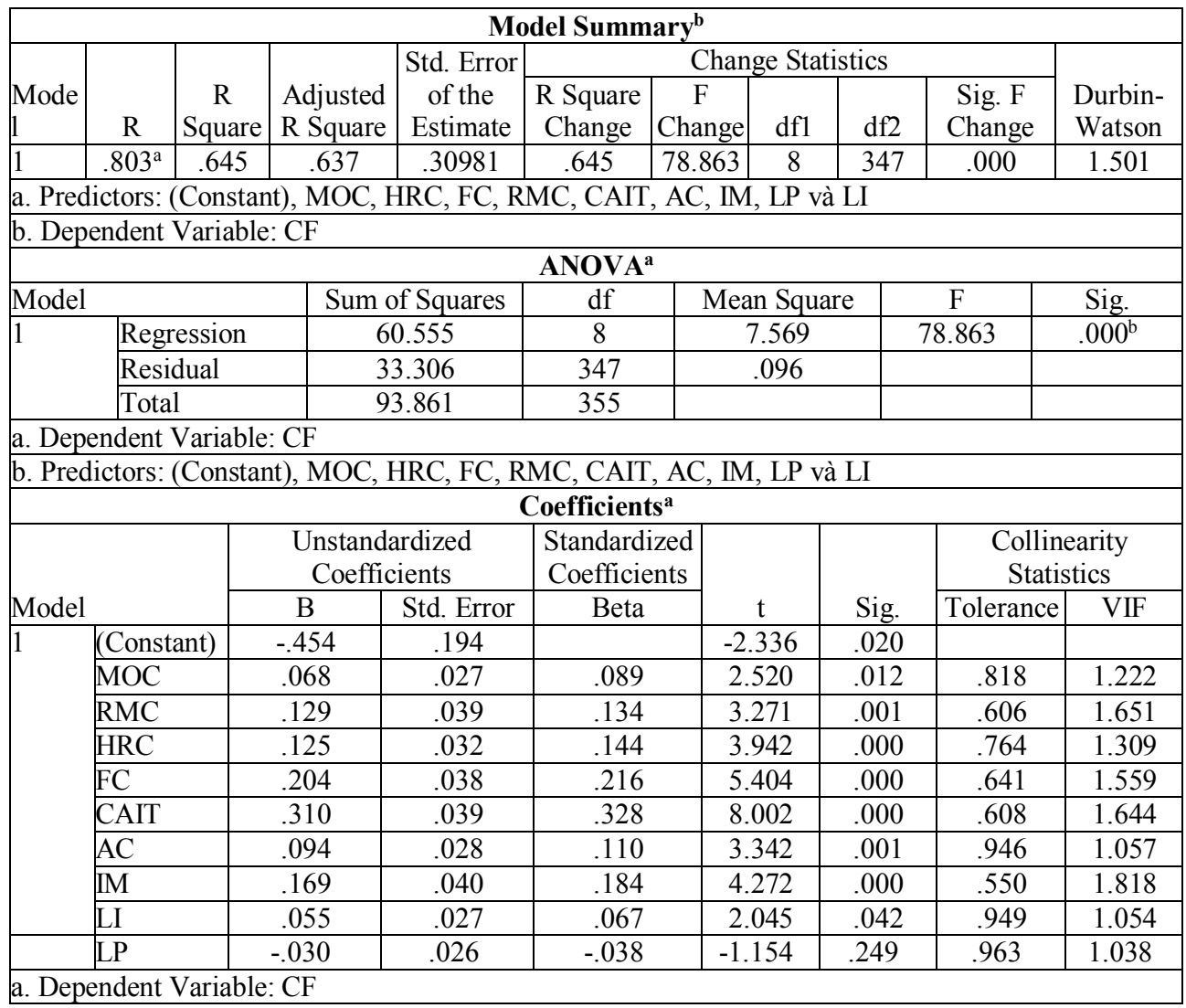

\section{Discussion}

Based on the standardized Beta, we can assess the influence of factors: MOC, HRC, FC, RMC, CAIT, AC, IM, LP and LI. The greater the absolute value of Beta is, the stronger that factor influences Competitiveness of BR-VT firms, such as:

Competency to access and innovate technology has $\beta=0.332(\mathrm{p}=0.000)$, the largest among Beta coefficients shows that Competency to access and innovate technology in manufacturing is very important if we want to enhance competitive competence. This is entirely reasonable in a fiercely competitive market today, and similar to the findings of Karimi [13].

The second most influential factor is the Financial competency with $\beta=0.216$ ( $p=$ 0.000), BR-VT enterprises often lack capital, especially in the aquatic harvest season, the state needs to expand pilot lending programs for with the model of linkage, high technology application and service of fisheries towards wide application nationwide. This point is consistent with the research of Thompson [24].

The third most influential factor is Impact on the market with $\beta=0.184(p=0.000)$, when we have good and safe products, we have good market share in the market; receive information, process to predict market changes, and then give directions to enterprises [22]. This is not consistent with the research of Thompson [24].

The fourth most influential factor Relationship marketing competency has $\beta=0.144$ ( $p$ $=0.000$ ). Some studies conclusively confirm that some characteristics are positively and 
significantly associated with small business growth while others find insignificant relationships [13].

The fifth influential factor Human resource competency has $\beta=0.1134$ ( $\mathrm{p}=$ 0.001).Delgado [16] stated that management skills are an important factor for the growth of small businesses and the lack of management skills is a barrier to growth and one of the factors that can lead to losses lose.

The sixth influential factor Adaptive competency has $\beta=0.110(\mathrm{p}=0.001)$, the strong influence shows that technical, economic and policy aspects, adaptive capacity depends on the individual's ability, community and organization to adapt to adversity and events and it is their creative, flexible and novel approach to addressing market changes [4]. This research result is similar to that of Thompson [24].

The 7th influential factor Management and operating competency of enterprises has $\beta=$ 0.089 ( $p=0.012$.It is very important and through these factors businesses can improve their competitiveness. The results of this study are similar to the results of Thompson [24].

The 8th lowest influencing factor Local infrastructure has $\beta=0.067(p=0.042)$, this factor helps businesses detect opportunities and business barriers based on customer knowledge, competitors and market forces [34].This result is consistent with the research of Flanagan [26], it is necessary to promote trade promotion, promotion and diversification distribution channels.

The 9th influence factor is Laws and policies with, not statistically significant because the coefficient $\beta=-0.038$ ( $p=0.249$ ) has an opposite effect with the competitive capability of the BR-VT enterprises, showing that difficulties from policies and laws affecting the production of enterprises, making the competitiveness of enterprises weak [35]. Although the legal system and policies are not comprehensive, complete and uniform, businesses acknowledge the government's growing interest in and support for businesses, including BR-VT enterprises [36].

Testing the difference of competitive capability, according to individual characteristics shows that there is no difference between men and women, different working positions, different business sizes, and different educational levels when assessing the level influence of competitive competence. But there is a statistically significant difference in the impact level of Competitive capability among different working seniority groups.

\section{Conclusions}

Not only seafood managers but many industries need to know the increasing of business seafood activities and use research and data analysis to increase activities in their business.

This research has proved that competition is not a new concept, but a topic of increasing interest among scholars and international organizations, government and private enterprises in general. Recognizing and fulfilling these obligations is often a challenge for the fisheries sector. Preliminary and informal research has hypothesized that fisheries seem to have special and identifiable tasks in the competitive sector but the relationship of those actions to the development of enterprises in BR-VT and the sustainability of the competitive capability are unclear.

The businesses are self-motivated to improve themselves more and more constantly developing and developing more comprehensively by the competition. Frozen seafood processing enterprises in BR-VT province are facing many opportunities but also challenges from inside and outside, so strengthening competitiveness should be set as a central task for whole seafood industry.

The research is limited because it is only conducted in one locality; the small sample only represents two-thirds of enterprises across BR-VT province. The scope of the research 
topic is a big issue, so it takes time to test and complete the system of arguments and proposals.

\section{References}

1. T. Trondsen, Marketing of Seafood Product - Trends and Challenges (Zaragoza, Spain, 2007).

2. E. Di Maria, S. Micelli. SMEs and Competitive Advantage: a Mix of Innovation, Marketing and ICT. The Case of "Made in Italy" (2008). www.decon.unipd. it/assets/pdf/wp/20080070.pdf

3. FAO, The 2030 agenda and the sustainable development goals: the challenge for aquaculture development and management. FAO Fisheries and Aquaculture Circular. (Rome, 2017).

4. T. Trondsen, The Canadian Geographer 56(4), 459 (2012).

5. N. Sytnyk, I. Onyusheva, Y. Holynskyy, Polish J. of Management Studies 19(2), 445 (2019).

6. K.B. Lindkvist, T. Trondsen, J. Xie, Marine Policy 32(3), 432-441 (2008).

7. A. Thompson, A. Strickland, Crafting and executing strategy (McGraw Hill, Irwin, 2001).

8. M. Porter, M. Kramer, Harvard Business Review 89(1), 2 (2011).

9. C. Ketels, Clusters and Competitiveness: Porter's Contribution (Oxford, Oxford University Press, 2011).

10. M. Anoop, Business Research Quarterly 17(2), 77 (2014).

11. G. Hult, M. Tomas, D. Ketchen, S. Slater, Strategic Management J. 26, 1173 (2005).

12. J. Narver, S. Slater, J. of Marketing 54, 20 (1990).

13. S. Karimi, H. Naghibi, International J. of Information, Business and Management, 7(4), 86 (2015).

14. C. Ketels, Journal of Industry, Competition and Trade 6(2), 115 (2006).

15. D. Teece, Strat. Manag. J. 28(13), 1319 (2007).

16. M. Delgado, C. Ketels, M. Porter, S. Stern. NBER Working Paper 18249 (2012).

17. C. Prahalad, V. Ramaswamy, The Future of Competition: Co-creating Unique Value with Customers (Harvard Business School Press, Cambridge, 2004).

18. K.G. Grunert, L.F. Jeppesen, K.R. Jespersen, A.M. Sonne, K. Hansen, T. Trondsen, J.A. Young, European Journal of Marketing (2005).

19. H. Van, I. Onyusheva, D. Ushakov, R. Santhanakrishnan, Int. J. of Energy Economics and Policy 8(4), 21 (2018).

20. B. Barney, J. of Management 17(1), 99 (1991).

21. B. T. Duy, T. H. Ai, EUrASEANs 1(14), 51 (2019).

22. A. Sauka, Measuring the Competitiveness of Latvian Companies (2015).

23. D. Teece, J. of International Business Studies 8, 37 (2014).

24. A. Thompson, A. Strickland, Crafting and executing strategy (McGraw Hill. Irwin, 2001).

25. K.H. Chi, Corporate governance: an international review 13(2), 211 (2005) 
26. R. Flanagan, W.Lu, L.Shen, C. Jewell, Construction Management and Economics 25(9), 989 (2007).

27. J. Abor, P. Quartey. Int. Res. J. Finan. Econ. 39, 218 (2010).

28. D. Walters, G. Lancaster, Management Decision 38(3), 160 (2000).

29. W. Kohler, J. of Industry, Competition and Trade 6(2), 85 (2012)

30. M. Lewrick, Changes in Innovation Styles: Comprehensive Study of the Changes in Innovation Styles to Identify the Causes and Effects of Different Influencing Factors and Capabilities to Create a General Innovation Pattern (Doctoral dissertation, Edinburgh Napier University Business School, Edinburgh Napier University, 2007).

31. Momaya, Development of Competitive Strategy (Hindustan Publishing Co. New Delhi. (2004).

32. G. T. Lumpkin, G. Dess, The Academy of Management Review 21(1), 135 (1996).

33. I. Sentosa, J. of Arts, Science and Commerce 3(1), 75 (2012).

34. C. Corbett, L. Wassenhove, California Management Review 35(4), 107 (1993).

35. T. H. Ai, EUrASEANs 4(11), 17 (2018).

36. O. Sivash, D. Ushakov, M. Ermilova, IOP Conf. Series: Earth and Environ. Science 272(3), 2 (2019) 